\title{
Knowledge \& Awareness about COVID-19 and the Practice of Respiratory Hygiene and Other Preventive Measures among Patients with Diabetes Mellitus in Pakistan
}

\author{
Kumar Ajay, \\ Jinnah Postgraduate Medical Centre, Pakistan \\ Ishfaq Hamza, \\ Shifa College of Medicine, Pakistan \\ Khemani Deepika, \\ Jinnah Sindh Medical University, Pakistan \\ Ghori, Qurat-ul-Ann Ramsha,
} Sindh Institute of Urology and Transplantation, Pakistan

Sohail Hamza, Hassan Syeda Maria, Jinnah Sindh Medical University, Pakistan

Ghazanfar,Shamas, Dow University of Health Sciences, Pakistan

Khan Muhammad Adil Aftab,

Shifa College of Medicine, Pakistan

Ahmed Moiz,
Abbas Kiran,

Jinnah Postgraduate Medical Centre, Pakistan

\begin{abstract}
COVID-19 is a global pandemic that has emerged and it is rapidly spreading throughout the world and subsequently causing great damage to the global economy and health-care. Patients with diabetes or other comorbidities are at a greater risk of developing severe illness. Knowledge and awareness are key elements to stimulate practice of preventive measures. The present study evaluated the level of knowledge and awareness about COVID-19 among individuals with diabetes and their compliance with the preventive measures against it. A total of 242 individuals who were diagnosed with diabetes mellitus and were 18 years or older participated in the study. The data was collected using an interview based questionnaire. Data was analyzed
\end{abstract}


using Statistical Package for Social Sciences (SPSS) version 24. The mean age $\pm \mathrm{SD}$ of the study population was $50.78 \pm 11.24$ years. In this study, 215 $(88.8 \%)$ participants were aware that COVID-19 is caused by a virus and the disease is spread through droplets after sneezing or touching and shaking hands with an infected person (78.5\%). However, only half the study populace regularly monitored their glucose level and complied with the "sick day rules" that is applicable during this pandemic. The present study indicates that despite the adequate knowledge and awareness about the coronavirus disease, the study participants were non-compliant with the practice of preventive and precautionary measures against the pandemic.

Keywords: Covid-19, Diabetes Mellitus, Prevention

\section{Introduction}

In December 2019, a novel coronavirus responsible for the development of respiratory disease was traced back to origins in Wuhan, China (Zhu et al., 2020). Its notoriety quickly gained traction as it began spreading at nearly unprecedented rates. It would later be known as Covid-19. The novel coronavirus is an RNA positive virus which shares similar clinical manifestations to the other members of the same family, such as MERS and SARS (Guo et al., 2020).

The primary symptoms of those infected seem to be inclusive of fever, cough and dyspnea, followed by respiratory failure in most lethal instances of pathogenesis. Some distinguishing features of Covid-19 include gastrointestinal symptoms such as diarrhea and vomiting, which were observed with substantially less frequency in the other members of the coronavirus family that are associated with respiratory disease (Huang et al., 2020). Covid-19 was declared a pandemic by the WHO on March 11, 2020.

The Case Fatality Ratio seems to differ drastically by region, and is highest in Italy, where it was estimated to stand at nearly $7.7 \%$ in most recent studies (Lazzerini \& Putoto, 2020). The fatality of the disease also differs within certain demographics, and is particularly high with those who have preexisting conditions as well as those who older than fifty years of age $\mathrm{Xu}$ et al., 2020).

One of the most concerning aspects of this virus is its rate of transmission. The basic reproductive number of Covid-19 is estimated to be above that of the influenza virus and well within the range of SARS. Yet, Covid-19 has infected a greater portion of the population than MERS, implying a greater degree of transmissibility than many of the diseases preceding it (Liu, Y., Gayle, A. A., Wilder-Smith, A., \& Rocklöv, J., 2020). Although different means of treatment have been claimed to decrease mortality, further research and clinical interventions are required $(\mathrm{Xu}$, et al., 
2020). Due to the lack of a vaccine and limited treatment options, the best mitigation strategy is through a decrease in person-to-person contact. Thus, many preventative measures have been imposed by Health organization and ministries etc. which primarily serve to limit direct physical interaction within large groups.

Recent literature indicates that COVID-19 patients who had a preexisting disease including cardiovascular disease and diabetes are at a higher risk of developing severe illness with $2019 \mathrm{nCoV}$ compared to those who are healthy. A study by Xiaobo Yang in 2020 assessed 32 patients who died of COVID-19 and reported that out of the 32 fatalities, 22\% were diabetic (2020). Another study with over thousand confirmed COVID-19 cases, reported that $16.2 \%$ of their patients had diabetes (Guan, et al., 2019). In addition, a study in 2019 surveying the prevalence of type 2 diabetes in Pakistan found that out of 18,856 participants, $16.98 \%$ were diabetic, indicating that the prevalence of the disease in Pakistan was much higher than previously thought (Aamir et al., 2019).

Hence, the study evaluated the knowledge, awareness and practices of diabetic patients to enable appropriate measures to be implemented targeting and concentrating on the vulnerable diabetic population in the community. Since Pakistan has poor resources, it will provide a ground for scientists to study the implications of the disease expansively and also provide insights to government agencies for strategy and policy development.

\section{Methodology}

This is a descriptive study which was conducted from February to March 2020 in Karachi, Sindh, Pakistan. A non-probability convenience sampling technique was used to recruit the participants for the study. The sample size was calculated using the following formulae:

$\mathrm{n}=\mathrm{N} * \mathrm{X} /(\mathrm{X}+\mathrm{N}-1)$,

Where,

$\mathrm{X}=\mathrm{Z}_{\alpha / 2}{ }^{2} * \mathrm{p} *(1-\mathrm{p}) / \mathrm{MOE}^{2}$ and $\mathrm{Z}^{\alpha / 2}=$ critical value of the normal distribution. By keeping the sample proportion; $p$ of diabetes mellitus in Pakistan as $16.98 \%$, the confidence level as $95 \%, \alpha$ as 0.05 , the critical value as 1.96, and the population size; $\mathrm{N}$ of more than one million, the sample size obtained was 217 (Aamir et al., 2019).

All individuals with diabetes mellitus type 2, aged 18 years or older, with some knowledge in English language were included in the study. The individuals with multiple comorbidities, diabetes type 1, and those who could not be contacted through electronic means were excluded from the study.

The aim of the study was to assess the knowledge, awareness, and practice of preventive measures of coronavirus disease among the diabetic population. The ethical approval was obtained by the institutional review 
board committee prior to the study. A verbal informed consent was obtained from each participant before starting the interview.

Due to the quarantine and lockdown in the city, it was not feasible for the authors to collect data via face to face interview. The authors had to improvise by using social media including WhatsApp, Facebook, Twitter, and Instagram to get the target population. The participants were further incentivized by means of a small monetary benefit to cover the cost of the internet bundles purchased by the participants. A preliminary survey was done recruit participants who fulfilled the eligibility criteria as mentioned above. Once the diabetic patients were identified, they were contacted through the phone numbers they provided. They were then informed about the aim of the study, the benefits of the study at individual and community levels, and assured them about the anonymity and confidentiality of the data being collected. Once the verbal consent had been obtained, the participants were interviewed for at least 25 to 30 minutes. The extensive interview covered the demographics characteristics, knowledge, awareness and practice details.

Demographic characteristics included the individual's age, gender, marital status, occupation, education, employment status, body mass index and hemoglobin A1C (HbA1c). The interview schedule questions were developed using the updated guidelines on COVID-19 by the National Health Service (NHS, 2020).

The data was recorded over the mobile device during the call. Statistical Package for Social Sciences (SPSS) version 24 was used for analysis. Continuous and categorical variables were represented as mean \pm SD and frequencies or percentages respectively.

\section{Results and Discussion}

A total of 242 patients with diabetes were sampled for the study. The mean age \pm SD of our sample was $50.78 \pm 11.24$ years. More than half of the study population; $62.8 \%$ were women. The majority of the participants had some level of formal education, and only 57 (23.5\%) participants had no formal education. The unemployment rate in our population was $1.6 \%$ (table 1). 
Table 1. Demographic Characteristics of Study Participants

\begin{tabular}{|c|c|}
\hline Item & n (\%) \\
\hline \multicolumn{2}{|l|}{ Age in years } \\
\hline 24 to 29 years & $41(9.5 \%)$ \\
\hline 30 to 44 years & $51(11.9 \%)$ \\
\hline 45 years or older & $24(5.6 \%)$ \\
\hline \multicolumn{2}{|l|}{ Gender } \\
\hline Male & $90(37.2 \%)$ \\
\hline Female & $152(62.8 \%)$ \\
\hline \multicolumn{2}{|l|}{ Marital Status } \\
\hline Married & $211(87.2 \%)$ \\
\hline Unmarried & $11(4.5 \%)$ \\
\hline Divorced/Separated & $1(0.4 \%)$ \\
\hline Widowed & $19(7.9 \%)$ \\
\hline \multicolumn{2}{|l|}{ Educational Status } \\
\hline Bachelor's Degree or higher & $93(38.4 \%)$ \\
\hline Higher Secondary Schooling & $52(21.5 \%)$ \\
\hline Primary Schooling only & $40(16.5 \%)$ \\
\hline No formal education & $57(23.5 \%)$ \\
\hline \multicolumn{2}{|l|}{ Occupation } \\
\hline Government & $22(9.1 \%)$ \\
\hline Private & $60(24.8 \%)$ \\
\hline Skill-related occupation & $27(11.2 \%)$ \\
\hline House wife & $96(39.7 \%)$ \\
\hline Unemployed & $23(9.5 \%)$ \\
\hline Retired & $13(5.4 \%)$ \\
\hline \multicolumn{2}{|l|}{ Employment Status } \\
\hline Government sector & $164(38.1 \%)$ \\
\hline Private sector & $135(31.3 \%)$ \\
\hline Business owner or Self-employed & $13(3.0 \%)$ \\
\hline Student & $112(26.0 \%)$ \\
\hline Unemployed & $6(1.4 \%)$ \\
\hline \multicolumn{2}{|l|}{ Pre-existing conditions } \\
\hline Cardiovscular & $145(59.9 \%)$ \\
\hline Cerebrovascular & $5(2.1 \%)$ \\
\hline Vascular & $10(4.1 \%)$ \\
\hline Multiple & $22(9.1 \%)$ \\
\hline$N K C M$ & $58(24.0 \%)$ \\
\hline
\end{tabular}

Out of the total 242 participants, less than half i.e. $102(42.1 \%)$, claimed that they were physically active while, only $1 / 5^{\text {th }}(21 \%)$ of the participants indulged in daily physical exercises. More than half of the participants had a cardiovascular disease concomitant with their diabetic condition (table 1).

Participants were well aware about the viral cause of the disease; 215 (88.8\%) and the route of transmission of the disease via droplets after sneezing or touching and shaking hands with an infected person; 78.5\%. The majority of them had a sound knowledge about the common flu like symptoms of 
COVID-19 but not of the rare symptoms including gastrointestinal and neurologic system (table 2).

Table 2. Knowledge \& Awareness about (COVID-19) among study participants

\begin{tabular}{|c|c|}
\hline Item & n $(\%)$ \\
\hline \multicolumn{2}{|l|}{ Coronavirus disease is caused by? } \\
\hline Virus & $215(88.8 \%)$ \\
\hline Bacteria & $14(5.7 \%)$ \\
\hline Congenital & $3(1.2 \%)$ \\
\hline Contaminated foods & $10(4.1 \%)$ \\
\hline \multicolumn{2}{|l|}{ The disease can transmitted through: } \\
\hline $\begin{array}{l}\text { Droplets after sneezing or touching and shaking } \\
\text { hands with an infected person }\end{array}$ & $190(78.5 \%)$ \\
\hline Eating infected food items & $150(61.9 \%)$ \\
\hline Blood transfusions & $70(28.9 \%)$ \\
\hline Sexual intercourse & $24(10.0 \%)$ \\
\hline Mosquito bites & $40(16.5 \%)$ \\
\hline \multicolumn{2}{|l|}{ What are the signs and symptoms of the disease? } \\
\hline High grade fever & $200(82.6 \%)$ \\
\hline Shortness of breath (Respiratory symptoms) & $215(88.8 \%)$ \\
\hline Diarrhea, and other GIT symptoms & $46(19.0 \%)$ \\
\hline Neurological symptoms & $17(7 \%)$ \\
\hline \multicolumn{2}{|l|}{ Are antibiotics effective against the COVID-19? } \\
\hline Yes & $26(6.0 \%)$ \\
\hline No & $172(71.1 \%)$ \\
\hline Not sure & $44(18.2 \%)$ \\
\hline \multicolumn{2}{|l|}{ Does smoking aggravates the disease? } \\
\hline Yes & $156(64.4 \%)$ \\
\hline No & $28(11.5 \%)$ \\
\hline Not sure & $58(23.9 \%)$ \\
\hline \multicolumn{2}{|l|}{$\begin{array}{l}\text { Can extreme temperatures (very cold or very hot) } \\
\text { destroy the virus? }\end{array}$} \\
\hline Yes & $174(71.9 \%)$ \\
\hline No & $35(14.4 \%)$ \\
\hline Not sure & $33(13.6 \%)$ \\
\hline \multicolumn{2}{|l|}{$\begin{array}{l}\text { Do vaccines against pneumococcal or influenza } \\
\text { vaccine protect you against the COVID-19? }\end{array}$} \\
\hline Yes & $13(5.3 \%)$ \\
\hline No & $214(88.4 \%)$ \\
\hline Not sure & $15(6.1 \%)$ \\
\hline \multicolumn{2}{|l|}{$\begin{array}{l}\text { Identify the high risk groups for coronavirus } \\
\text { disease: }\end{array}$} \\
\hline Elderly & $175(72.3 \%)$ \\
\hline $\begin{array}{l}\text { Those with pre-existing medical conditions like } \\
\text { Diabetes Mellitus, Hypertension, etc. }\end{array}$ & $186(76.8 \%)$ \\
\hline Neonates and young children & $115(47.5 \%)$ \\
\hline \multicolumn{2}{|l|}{$\begin{array}{l}\text { Can the virus survive on hard surfaces like table, } \\
\text { chairs, etc.? }\end{array}$} \\
\hline Yes & $132(54.5 \%)$ \\
\hline No & $100(41.3 \%)$ \\
\hline Not sure & $10(4.1 \%)$ \\
\hline
\end{tabular}


The study participants were also well-informed about the high-risk groups. For instance, 186/242 individuals were aware that individuals with pre-existing conditions like diabetes and hypertension are at risk of developing critical illness with the novel coronavirus (table 2).

Table 3. Practice of Preventive Measures against COVID-19 among study participants

\begin{tabular}{ll}
\hline Item & n (\%) \\
\hline Wash your hands frequently & $217(97.1 \%)$ \\
Maintain social distancing & $183(87.9 \%)$ \\
Maintain at least 1m or 3ft distance between yourself and & $177(80.7 \%)$ \\
anyone who is coughing or sneezing & \\
& \\
Avoid touching eyes, nose and mouth & $211(91.1 \%)$ \\
Cover your mouth and nose with your bent elbow or tissue & $207(94.7 \%)$ \\
when you cough or sneeze & \\
Stay home when you are sick, except to get medical care. & $213(90 \%)$ \\
Wash your hands often with soap and water for at least 20 & $189(90.5 \%)$ \\
seconds, especially after going to the bathroom; before & \\
eating; and after blowing your nose, coughing, or sneezing. & \\
\hline Precautionary Diabetes-related Practices among Participants \\
\hline Item & Frequency \\
& $(\mathbf{m})$ \\
\hline Monitor blood sugar level before and after meals. & $120(49.5 \%)$ \\
Monitor the diet and calorie intake. & $140(79.2 \%)$ \\
Regularly check the feet for any changes or injuries. & $49(20.2 \%)$ \\
Monitoring of cholesterol levels on regular intervals. & $123(50.8 \%)$ \\
Evaluation of Hemoglobin Alc, recently. & $140(57.9 \%)$ \\
Urinalysis & $107(44.2 \%)$ \\
Proper dental hygiene. & $203(83.9 \%)$ \\
Administration of pneumococcal vaccine in past 5 years. & $7(2.9 \%)$ \\
Administration of Influenza vaccine in the last one year. & $12(5.0 \%)$ \\
\hline & \\
\hline
\end{tabular}

Despite adequate knowledge and awareness about the coronavirus disease, the study found out that many individuals with diabetes were noncompliant with the preventive measures against the disease and only a minority was taking extra precautions for the optimum management of the diabetes mellitus during the current pandemic. A thorough review recently published by Chen, et al. (2020), reported that patients with diabetes, hypertension or other cardiovascular disease are associated with a worse prognosis during the COVID-19 illness. The International Diabetes Federation has advised people with diabetes mellitus to plan ahead of time what to do before they get sick and further recommended to practice the "sick day rules", including; keeping oneself hydrated, regularly monitoring the blood glucose level, temperature and other symptoms of a viral disease and taking medication as recommended and at the right time (International Diabetes 
Federation Europe, 2020). In our study, only half the population claimed to monitor their blood sugar levels using a glucometer.

The findings of the present study indicate that majority of the participants were well aware and had handsome knowledge about the coronavirus disease. As listed in Table 1, this can be attributed to their evidently high education status with about 93 (38.4\%) participants having graduated from a college, $52(21.5 \%)$ participants who with higher secondary school education and only a small percentage of 57 (23.5\%) participants with no formal education. In one of the earlier papers, the authors assessed the awareness level about the complications of uncontrolled diabetes mellitus and found a link between higher education status with greater awareness and better attitude towards diabetes among their participants (Belsti, Akalu, Fekadu, and Animut, 2019).

In the present paper, the majority of the participants were women. An earlier paper from Saudi Arabia on the MERS epidemic concluded that gender was a significant indicator of concern for the epidemic whereas knowledge was the only predictor for both precaution and concern (Almutairi et al., 2015). The earlier surveys from China by Zhong et al., 2020 demonstrated a similar propensity towards statistical deviation in regards to preventative practices of different demographics on basis of gender, marital status, and education level. Thus, there must be intrinsic variables at play in each demographic setting which affect the preventive measures that are subsequently taken within a specific demographic setting. These intrinsic variables may take the form of differences in media consumption, alternative sources of news, or even innate psychological tendencies due to biological differences.

Further research should be conducted in order to extract more evidence regarding the underlying variables that may have an impact on the behavior, attitude and practice of preventive measures against coronavirus pandemic in high-risk populace.

\section{Limitations of the study}

Despite the best efforts to generalize the findings of the present study, it still poses many limitations pertaining to the generalizibility of the findings to the majority of the Pakistani population. This arises from the fact that the recruitment of study participants was done through the convenience sampling technique leading to the sample bias. However, the sample size was large and it is hoped that this study can serve as a catalyst for more rigorous and prolonged assessments of knowledge of COVID-19 across diverse groups so that a generalize policy can be developed irrespective of the demographic limitations. 


\section{Conclusion}

The present study indicates that despite the adequate knowledge and awareness about the coronavirus disease, the study participants were noncompliant with the practice of preventive and precautionary measures against the pandemic. The current knowledge can be applied to develop strategies and policies that are more focused to incentivize the high-risk individuals to practice proper preventive measures as directed by the respective health authorities and ministries.

\section{References:}

1. Aamir, A. H., Ul-Haq, Z., Mahar, S. A., Qureshi, F. M., Ahmad, I., Jawa, A., Sheikh. A, Raza A., Fazid S., Jadoon Z., Ishtiaq O., Safdar N., Afridi H., Heald, A. H. (2019). Diabetes Prevalence Survey of Pakistan (DPS-PAK): prevalence of type 2 diabetes mellitus and prediabetes using HbAlc: a population-based survey from Pakistan. BMJ Open, 9(2). doi: 10.1136/bmjopen-2018-025300

2. Almutairi, K. M., Helih, E. M. A., Moussa, M., Boshaiqah, A. E., Alajilan, A. S., Vinluan, J. M., \& Almutairi, A. (2015). Awareness, Attitudes, and Practices Related to Coronavirus Pandemic Among Public in Saudi Arabia. Family \& Community Health, 38(4), 332-340. doi: 10.1097/fch.0000000000000082

3. Belsti, Y., Akalu, Y., Fekadu, H., \& Animut, Y. (2019). Awareness of complications of diabetes mellitus and its associated factors among type 2 diabetic patients at Addis Zemen District Hospital, northwest Ethiopia. BMC Research Notes, 12(1). doi: 10.1186/s13104-0194637-x

4. Home. (2020, March 25). Retrieved April 2, 2020, from https:/www.idf.org/our-network/regions-members/europe/europenews/196-information-on-corona-virus-disease-2019-covid-19outbreak-and-guidance-for-people-with-diabetes.html.

5. Guan, W., Ni, Z., Hu, Y., Liang, W., Ou, C., He, J., Liu, L., Shan, H., Lei, C., Hui, D. S. C., Du, B., Li, L., Zeng, G., Yuen, K.-Y., Chen, R., Tang, C., Wang, T., Chen, P., Xiang, J., ... Zhong, N. (2020). Clinical Characteristics of Coronavirus Disease 2019 in China. New England Journal of Medicine. doi: 10.1056/nejmoa2002032

6. Guo, Y.-R., Cao, Q.-D., Hong, Z.-S., Tan, Y.-Y., Chen, S.-D., Jin, H.J., ... Yan, Y. (2020). The origin, transmission and clinical therapies on coronavirus disease 2019 (COVID-19) outbreak - an update on the status. Military Medical Research, 7(1). doi: 10.1186/s40779-02000240-0

7. Huang, C., Wang, Y., Li, X., Ren, L., Zhao, J., Hu, Y., Zhang, L., Fan, G., Xu, J., Gu, X., Cheng, Z., Yu, T., Xia, J., Wei, Y., Wu, W., Xie, 
X., Yin, W., Li, H., Liu, M., ... Cao, B. (2020). Clinical features of patients infected with 2019 novel coronavirus in Wuhan, China. The Lancet, 395(10223), 497-506. doi: 10.1016/s0140-6736(20)30183-5

8. Lazzerini, M., \& Putoto, G. (2020). COVID-19 in Italy: momentous decisions and many uncertainties. The Lancet Global Health. doi: 10.1016/s2214-109x(20)30110-8

9. Li, B., Yang, J., Zhao, F., Zhi, L., Wang, X., Liu, L., Bi, Z., \& Zhao, Y. (2020). Prevalence and impact of cardiovascular metabolic diseases on COVID-19 in China. Clinical Research in Cardiology. doi: 10.1007/s00392-020-01626-9

10. Liu, Y., Gayle, A. A., Wilder-Smith, A., \& Rocklöv, J. (2020). The reproductive number of COVID-19 is higher compared to SARS coronavirus. Journal of Travel Medicine, 27(2). doi: $10.1093 / \mathrm{jtm} / \mathrm{taaa} 021$

11. Xu, Z., Shi, L., Wang, Y., Zhang, J., Huang, L., Zhang, C., Liu, S., Zhao, P., Liu, H., Zhu, L., Tai, Y., Bai, C., Gao, T., Song, J., Xia, P., Dong, J., Zhao, J., \& Wang, F.-S. (2020). Pathological findings of COVID-19 associated with acute respiratory distress syndrome. The Lancet Respiratory Medicine, 8(4), 420-422. doi: 10.1016/s22132600(20)30076-X

12. Yang, X., Yu, Y., Xu, J., Shu, H., Xia, J. 'an, Liu, H., Wu, Y., Zhang, L., Yu, Z., Fang, M., Yu, T., Wang, Y., Pan, S., Zou, X., Yuan, S., \& Shang, Y. (2020). Clinical course and outcomes of critically ill patients with SARS-CoV-2 pneumonia in Wuhan, China: a single-centered, retrospective, observational study. The Lancet Respiratory Medicine. doi: 10.1016/s2213-2600(20)30079-5

13. Zhong, B.-L., Luo, W., Li, H.-M., Zhang, Q.-Q., Liu, X.-G., Li, W.T., \& Li, Y. (2020). Knowledge, attitudes, and practices towards COVID-19 among Chinese residents during the rapid rise period of the COVID-19 outbreak: a quick online cross-sectional survey. International Journal of Biological Sciences, 16(10), 1745-1752. doi: 10.7150/ijbs.45221

14. Zhu, N., Zhang, D., Wang, W., Li, X., Yang, B., Song, J., Zhao, X., Huang, B., Shi, W., Lu, R., Niu, P., Zhan, F., Ma, X., Wang, D., Xu, W., Wu, G., Gao, G. F., \& Tan, W. (2020). A Novel Coronavirus from Patients with Pneumonia in China, 2019. New England Journal of Medicine, 382(8), 727-733. doi: 10.1056/nejmoa2001017 